Doi: $10.22478 /$ ufpb.1983-1579.2018v3n11.42333 http://periodicos.ufpb.br/ojsz/index.php

\title{
TÃO PERTO E TÃO LONGE: escolas próximas a unidades de conservação e os desafios para a ambientalização do currículo
}

\author{
SO CLOSE, TOO FAR: schools next to conservation areas and the challenges for the \\ environmentalization of the schools' curriculum
}

\author{
Taís Cristine Ernst Frizzo ${ }^{1}$ \\ Isabel Cristina de Moura Carvalho²
}

\begin{abstract}
Resumo: Este artigo tem como objetivo compreender os aspectos que motivam a aproximação ou que dificultam as relações entre escolas e unidades de conservação. Busca, também, observar se essas relações influenciam na ambientalização do currículo escolar. Os estudos foram realizados a partir de uma abordagem etnográfica, em escolas próximas a unidades de conservação em Porto Alegre e Viamão, RS, entre 2014 e 2018. Observaram-se fatores que facilitavam a aproximação entre as escolas e as unidades de conservação, como os investimentos dos funcionários das unidades de conservação na promoção da educação ambiental nas escolas, a presença de professores e de gestores engajados com as questões ambientais, e os incentivos de políticas públicas, como o "Programa Mais Educação" e a legislação referente à educação ambiental. Outros elementos, ao contrário, impediam ou dificultavam essa relação, entre os quais podemos citar a carência de recursos humanos e financeiros, a violência nos locais, os limites de certas políticas educacionais - que podem levar a uma rigidez no currículo -, a imposição das regras de acesso e de uso das unidades de conservação e os conflitos históricos da implantação destas instituições no Brasil.
\end{abstract}

Palavras-chave: Ambientalização do currículo. Unidades de Conservação. Escola. Educação Ambiental.

\section{INTRODUÇÃO}

Parece óbvio dizer que as escolas se relacionam com o lugar onde estas estão geograficamente situadas. Afinal, elas fazem parte da vida dos bairros, das cidades e das comunidades do entorno que atendem. Até mesmo a política pública garante que as crianças se matriculem nas escolas mais próximas de sua moradia (por exemplo, Estatuto da Criança e do Adolescente, Portaria SEC/RS No 260/2017). Contudo, esta noção de que a escola pertence ao lugar, perde de imediato sua obviedade se pensamos em escolas próximas a unidades de conservação. Essa foi a pergunta que moveu minha pesquisa de

\footnotetext{
${ }^{1}$ Professora do Departamento de Ciências Exatas e da Natureza, Colégio de Aplicação, Universidade Federal do Rio Grande do Sul. E-mail: <taisfrizzo@hotmail.com>

2 Pesquisadora visitante da UFRGS, atuando no Programa de Pós-Graduação em Antropologia. E-mail: <isacrismoura@gmail.com>
}

Abstract: This article aims to identify what aspects can facilitate or hinder the connections between schools and conservation areas. It also seeks to observe if these relations influence the environmentalization of the school's curriculum. The study was carried out from an graphic approach in schools near conservation between 2014 and 2018. Factors that facilitated the connections between schools and conservation areas identified in this research are: investments by conservation unit officials in promoting environmental education in schools; the presence of teachers and hampered or banned this relationship. For instance, lack of human and financial resources; violence in the localities; limitations in educational policies - which can lead to rigidity in the curriculum -, the imposition of rules for access and use of conservation areas; and the historical conflicts generated by the implementation of conservation areas in Brazil.

Keywords: Ambientalization of the curriculum. Conservation areas. School. Environmental Education. 
doutorado. $\mathrm{O}$ que eu pretendia saber eram quais as relações que as escolas que estão nos limites, ou mesmo dentro de unidades de conservação, estabelecem com essas áreas e com as políticas de conservação da natureza. Em outras palavras, em que medida o currículo escolar - no sentido amplo de currículo - expressa esta condição de avizinhar-se ou mesmo de pertencer a uma área natural protegida? Haveria uma orientação ambiental nessas escolas mais do em outras que estão longe de ambientes naturais? Elas se ocupariam da discussão dos problemas e das questões ambientais na formação de seus estudantes? Essas perguntas me inquietavam porque eu mesma trabalho numa escola que é vizinha a uma área natural, reconhecida como unidade de conservação pela Universidade Federal do Rio Grande do Sul (UFRGS)3. Por isso, comecei pelo "quintal de casa", isto é, comecei a investigar porque na escola em que trabalho e em outras da região não se usava mais frequentemente esse ambiente natural para saídas de estudo, sobretudo no ensino de Ciências, que é minha área específica.

Tendo em vista as perguntas acima colocadas, desenvolvi esta pesquisa entre 2014 e 2018, sob orientação da professora Isabel Cristina de Moura Carvalho, com quem escrevo este artigo. $O$ estudo, desenvolvido por ocasião de meu doutoramento no Programa de Pós-Graduação em Educação da Pontifícia Universidade Católica do Rio Grande do Sul (PUCRS), se deu junto ao grupo de pesquisa "SobreNaturezas: epistemologias ecológicas"4.

Apesar de ter iniciado a pesquisa em um local bem conhecido por mim, ou seja, em escolas localizadas no entorno do Refúgio de Vida Silvestre Morro Santana, em Porto Alegre, RS, obstáculos surgiram e nos levaram a buscar outros locais para o estudo, o que será detalhado mais adiante. Após um período de peregrinação por diversas escolas e unidades de conservação, cheguei em Itapuã, distrito de Viamão, RS, onde pude aprofundar a investigação, com o apoio do Parque Estadual de Itapuã e de algumas escolas da região.

Tendo como referência os campos da Educação e da Antropologia, o estudo se desenvolveu dentro de uma abordagem etnográfica, possibilitando uma aproximação com os interlocutores, bem como uma abertura ao universo de explicações dos fenômenos estudados. Entendendo que os modos de ação relacionados à questão ambiental na escola são distintos, essa perspectiva permitiu conviver dentro do cotidiano escolar e observar a diversidade de práticas, produções e perspectivas dos diferentes atores.

Reunidas essas informações iniciais, explico que este artigo trata da pesquisa que empreendi tendo como questão orientadora entender como a escola se relaciona com as unidades de conservação, considerando o lugar em que está inserida e observando os fatores que podem influenciar na ambientalização do currículo. Assim, o objetivo foi identificar e compreender as questões que agem em prol da ambientalização do currículo ou que se constituem como desafios para esse processo, bem como os fatores que motivam a aproximação ou que dificultam as relações entre as escolas e as unidades de conservação. Aqui cabe destacar que as unidades de conservação, além de preservarem os ecossistemas, ao serem reconhecidas como tal passam a integrar um conjunto de políticas de educação ambiental e de conservação da natureza que de algum modo pode influenciar o contexto pedagógico dessas instituições.

O tema de interesse está relacionado aos processos de ambientalização do currículo na Educação Básica, ou seja, aos modos como a questão ambiental vem se construindo nas escolas, seja em função da educação ambiental ou dos outros processos que corroboram com a ambientalização desses espaços educadores.

\footnotetext{
${ }^{3} \mathrm{~A}$ área a qual me refiro é o Refúgio de Vida Silvestre Morro Santana, estabelecido pelo Conselho Universitário da UFRGS em 2006. No entanto, até hoje a área não foi inserida em em nenhum sistema de unidades de conservação, o que dificulta sua efetivação e conservação.

${ }^{4} \mathrm{O}$ grupo de pesquisa foi coordenado pela professora Isabel Cristina de Moura Carvalho, atual pesquisadora da Universidade Federal do Rio Grande do Sul, até 2017, passando então à coordenação dos professores Carlos Alberto Steil e Carmen Roselaine de Oliveira Farias, da UFRGS e da Universidade Federal Rural de Pernambuco, respectivamente.
} 
A ambientalização é definida por Carvalho et al. (2011) como um processo no qual a preocupação ambiental é internalizada, individualmente, na consciência dos indivíduos, e coletivamente, nas relações sociais e institucionais. Com relação aos processos de ambientalização do currículo, os autores destacam a importância das práticas pedagógicas como "operadores de legitimidade social, de crença e de identidade cultural” (p. 39). Com relação à escola, Nunes e Carvalho (2010) afirmam que, para além do tratamento dos conceitos epistemológicos e metodológicos referentes à problemática ambiental, a ambientalização do currículo deve ser encarada como a produção de uma cultura ambiental, onde se incluiriam saberes, práticas, valores, éticas e sensibilidades ambientais gerados em determinados processos educativos.

Assim, compreendemos o conceito de ambientalização como o conjunto de ações relacionadas à orientação ambiental da escola, as quais são influenciadas pelos diferentes fatores já referidos na literatura, como colocado acima, e também o observado nas experiências realizadas ao longo da pesquisa, como: as políticas públicas e os recursos públicos e privados disponíveis, as relações com a comunidade, a agência do lugar, a gestão escolar, o espaço físico, entre outros elementos que influenciam as decisões, dentro e fora da sala de aula (Frizzo, 2018). Dessa forma, a ambientalização do currículo integra, de forma abrangente, todas as ações que se referem às questões ambientais na escola, o que inclui a educação ambiental. Nesse sentido, diferentes autores referem que a educação ambiental pode ser compreendida como agente e efeito da ambientalização (Leite Lopes, 2006; Carvalho; Toniol, 2010; Farias, 2013; Borges, 2014). Farias (2013) reitera o caráter recursivo entre educação ambiental e ambientalização, demonstrando como a educação ambiental opera na internalização da questão ambiental nos indivíduos e nas instituições e, como efeito, resulta em ações que promovem a ambientalização.

Ao pensar a aproximação entre as unidades de conservação e as escolas, assim como nas possibilidades de promoção da ambientalização do currículo, entendemos que diferentes fatores se fazem presentes, o que implica em uma certa complexidade. Considerando o que observamos ao longo da pesquisa, nosso argumento é de que o lugar pode influenciar a ambientalização do currículo, mas que outros fatores, tais como as políticas para a conservação da natureza e para a educação, concorrem ao agir sobre os modos de constituição das ações ambientais nas escolas, assim como sobre as suas relações com as unidades de conservação.

Após esta introdução, começaremos apresentando brevemente as unidades de conservação que participaram do estudo. Após, serão abordadas as questões que se constituíram como desafios para a ambientalização do currículo nas escolas visitadas no período inicial da pesquisa, impedindo uma vínculo mais estreito entre essas instituições e a unidade de conservação localizada em sua proximidade. No tópico seguinte, traremos de um caso observado em campo, que se refere às relações entre a Escola Municipal de Ensino Fundamental Frei Pacífico e o Parque Estadual de Itapuã (PEI), e das estratégias utilizadas para a promoção da ambientalização do currículo. Por fim, observando as informações sobre a implantação do $\mathrm{PEI}$ e os conflitos relacionados à comunidade, analisaremos a influência que as políticas públicas (tanto educacionais como para a conservação da natureza) exercem na aproximação entre as unidades de conservação e as escolas.

\section{AS UNIDADES DE CONSERVAÇÃO E AS ESCOLAS}

As escolas que foram visitadas ao longo do estudo estão localizadas próximas às seguintes áreas preservadas, nos municípios de Viamão e de Porto Alegre, RS: Refúgio de Vida Silvestre Banhado dos Pachecos e Parque Estadual de Itapuã, que fazem parte do Sistema de Unidades de Conservação do Estado do Rio Grande do Sul; Parque Marechal Mascarenhas de Moraes e Reserva Biológica do Lami José Lutzenberger, sob a administração do Município de Porto Alegre, Refúgio de Vida Silvestre Morro Santana da UFRGS e Reservas Ecológicas da Escola Superior de Agricultura Luiz de Queiroz (ESALQ) da Universidade de São Paulo (USP), administradas pelas referidas universidades. Essas duas últimas e o Parque Marechal Mascarenhas de Moraes não fazem parte de sistemas de unidades de conservação, 
ainda que sejam contempladas em políticas de preservação dos órgãos que as mantém.

As Unidades de Conservação são sistematizadas com base no Sistema Nacional de Unidades de Conservação (Brasil, 2000), que define doze categorias, classificadas de acordo com a forma de proteção e com os usos permitidos em dois grupos: Unidades de Proteção Integral e Unidades de Uso Sustentável. Reserva Biológica, Parque e Refúgio de Vida Silvestre são Unidades de Proteção Integral, ou seja, têm como objetivo básico preservar a natureza, sendo permitido apenas o uso indireto dos seus recursos naturais. O Sistema Estadual de Unidades de Conservação (SEUC) é "constituído pelo conjunto de Unidades de Conservação federais, estaduais, municipais e particulares criadas no território do Estado" (Rio Grande do Sul, 2016), e segue as categorias de Unidades de Conservação estabelecidas no Sistema Nacional de Unidades de Conservação (SNUC).

As escolas visitadas são públicas e pertencem às redes dos municípios de Viamão ou de Porto Alegre ou à rede estadual do Rio Grande do Sul. Em sua maioria, tratam-se de escolas do campo.

Para a pesquisa foram utilizados recursos como observação participante, registros em diário de campo, entrevistas semiestruturadas (direcionadas aos profissionais das escolas e do Parque Estadual de Itapuã) e análise de documentos que orientam a ação das escolas e das redes de ensino. O trabalho de campo realizou-se entre 2015 e 2017. As informações oriundas dos interlocutores, da literatura e dos documentos foram consideradas na análise como base para a triangulação de fontes, conforme recomendado por Olivier de Sardan apud Forquilha (2013).

\section{VIOLÊNCIA, LIXO E CARRAPATO-ESTRELA: os desafios humanos e não humanos para a ambientalização do currículo}

Iniciando, em 2015, pelas escolas localizadas no entorno do Refúgio de Vida Silvestre Morro Santana, procuramos encontrar ações relacionadas ao uso e à valorização da área preservada. Ao contrário do que pensávamos, tais práticas não ocorriam, sendo impedidas por situações que dificultavam o acesso das escolas ao morro Santana.

Um dos problemas apresentou-se em uma visita a uma pequena escola de Ensino Fundamental da rede municipal de Viamão, quando a comunidade vivenciava uma disputa pelo comando do tráfico de drogas ilícitas, o que afetava diretamente a escola. A diretora relatou a ocorrência de tiroteios, inclusive durante o dia, e assassinatos de pessoas envolvidas no conflito. Muitos estudantes não estavam frequentando as aulas, pois havia o risco de ser alvejado por uma bala perdida no caminho para a escola; algumas famílias tinham partido para o litoral do RS e só voltariam quando a violência tivesse diminuído.

A escola recebera, em anos anteriores, oficinas de educação ambiental ministradas por professores e estudantes da UFRGS e promovera caminhadas nas trilhas com os estudantes. Contudo, com o advento do acirramento dos conflitos relacionados ao tráfico de drogas, a diretora não via possibilidade de continuar com as atividades no morro Santana.

A violência no local não é uma realidade recente, mas tem se aprofundado nos últimos anos. As dificuldades para acessar a área e as trilhas, associadas aos relatos sobre roubos e estupros, tráfico de drogas, abandono de carros roubados e de corpos de pessoas assassinadas, atingem as escolas, a comunidade e a própria universidade, já que muitas pesquisas são desenvolvidas no local. Tal situação não é exclusividade do morro Santana. Outras unidades de conservação inseridas na malha urbana também servem de refúgio para atividades ilícitas, causando insegurança na população, que cada vez se afasta mais desses ambientes, como se pode ver, por exemplo, nas pesquisas de Debetir (2006) e de Souza (2011). Em Santa Catarina, Debetir (2006) identificou conflitos relacionados à presença de fugitivos da polícia e de traficantes de drogas no Parque Municipal da Lagoinha do Leste e a Reserva Natural Menino Deus. No Paraná, Souza (2011) identificou a preocupação dos visitantes com relação à segurança como um dos principais fatores de desconforto para frequentar o no Parque do Cinturão Verde de Cianorte. 
Refletindo sobre o papel da violência nessas áreas, permanece a questão: como acessar esses ambientes naturais com objetivos de lazer, pesquisa, contemplação ou religiosidade, tendo que disputar este território com os seus usos ilícitos? A paisagem da violência se sobrepõe à paisagem natural de tal forma que acaba limitando o acesso da maioria da população, sejam quais forem seus motivos. Ações como "cortar o mato", por exemplo, se justificam pela necessidade de dificultar a instalação de ações criminosas nos locais. Esta realidade choca-se frontalmente com a idealização romântica da natureza onde as áreas naturais tendem a ser vistas como contraponto da própria degradação humana, associadas à uma construção cultural de natureza relacionada ao bem, ao belo e ao moralmente justo.

Nas atividades de educação ambiental em unidades de conservação encontramos o apelo para a conservação do ambiente frequentemente relacionada à perspectiva romântica. Como exemplo, podemos citar a pesquisa de Matos e Maria (2013), que buscaram observar a concepção de ambiente de estudantes que participaram de atividades de educação ambiental em um parque de São Paulo. De acordo com os autores, a visão de ambiente como sistema biológico esteve presente, mas também havia o entendimento de ambiente como natureza, na perspectiva romântica. Para eles, tais perspectivas estão relacionadas, respectivamente, ao tipo de abordagem realizada nas trilhas, que privilegiou explicações científicas sobre os processos naturais, e à corrente naturalista de educação ambiental, que incentiva a conservação do meio ambiente.

No morro Santana, um local evitado em função da violência, a natureza "real" transborda essa concepção romântica, sendo vinculada ao mal. A idealização romântica da natureza, que tanto sustenta as práticas ecológicas, é superada pela realidade. Carvalho (2009), ao tratar das "várias naturezas da natureza", mostra que os diferentes sentidos produzidos pelas pessoas influenciam as experiências e o agir político relacionados à natureza na contemporaneidade. As escolas, que poderiam ser pontes entre a comunidade e a unidade de conservação, acabam se tornando abrigos contra a violência que domina a região. As práticas ao ar livre, como caminhadas nas trilhas, são evitadas em função da segurança dos estudantes e dos professores.

Frente a tais dificuldades e seguindo nossa pergunta de pesquisa, percebemos que deveríamos pegar outra trilha. Assim, decidimos ampliar o estudo para outros locais. As próximas investidas desvelaram outra questão que tende a influenciar o currículo escolar: o investimento, ao tratar das questões ambientais, na problemática do lixo5.

Na maioria das escolas visitadas, ao perguntar para gestores ou professores sobre as questões ambientais, a resposta predominante referia-se às atividades relacionadas à separação dos resíduos. Como exemplo, foi observado o reaproveitamento de embalagens e caixas de mantimento usadas para a produção de revisteiros e de maquetes. Outra questão que chamava a atenção era a compra de coletores de resíduos, os quais serviriam para a separação a fim de encaminhar à coleta seletiva, com recursos do Programa Dinheiro Direto na Escola (PDDE) - Escola Sustentável ${ }^{6}$. De fato, tal ação entra em conflito com o problema da gestão dos resíduos nos municípios, pois nem todas as escolas que tinham os coletores contavam com um sistema de coleta seletiva satisfatório, de modo que os resíduos, quando separados, acabavam sendo novamente misturados. Em muitos locais a periodicidade da coleta seletiva não era suficiente para a quantidade de material separado.

Se recorrermos a outras pesquisas, como a de Loureiro et al. (2007) onde foram reunidos dados de escolas que realizam atividades de educação ambiental e os modos que utilizam para a destinação dos resíduos sólidos no Brasil, observamos algumas contradições. Em 2004, 49,3\% das escolas que promoviam a educação ambiental utilizavam a coleta periódica, mas um total de $41,3 \%$ procedia com a queima e

\footnotetext{
${ }^{5}$ Apesar de lixo ser compreendido como o conjunto de materiais não aproveitáveis, optamos por manter a palavra como referência da interlocução com as escolas visitadas.

${ }^{6}$ Os coletores de resíduos estão na lista de itens financiáveis pelo PDDE, em "Aquisição de materiais diversos para adequações ou manutenção no espaço físico da escola" (Brasil, 2014).
} 
menos de $5 \%$ das escolas reutilizavam ou reciclavam os resíduos. Ainda assim, segundo os autores houve uma diminuição de escolas que fazem educação ambiental e que jogam os resíduos em outras áreas ao invés de utilizar os demais recursos apontados, se comparados os dados obtidos em 2001, quando compunham um universo de $20,4 \%$, e em 2004 , com $11,9 \%$. Eles também observam que houve um aumento da porcentagem de escolas que oferecem educação ambiental e que queimam os resíduos, de $36,1 \%$ em 2001 para $41,3 \%$ em 2004.

Outra questão observada foram os tipos de abordagem utilizados para tratar da questão dos resíduos. Em muitos momentos as atividades se destinavam a classificar os resíduos em "recicláveis" e "não recicláveis" (mesmo que se tratassem de materiais reutilizáveis e não recicláveis). A crença na utopia da reciclagem é uma perspectiva amplamente difundida, e a escola não foge à regra. Quando tratamos a reciclagem como a tecnologia mitigadora dos danos causados pela produção de resíduos sólidos e, ao mesmo tempo, repassamos adiante parte das tarefas - já que separamos os resíduos e esperamos que o Estado dê continuidade ao processo - não estamos observando o processo como um todo, mas apenas de forma segmentada. Entre o cidadão separador de resíduos e a reciclagem há um longo caminho, cuja complexidade conta com fatores como o trabalho e a situação social dos recicladores, o valor comercial dos produtos reciclados, a poluição gerada no processamento da reciclagem, entre outros. E essas questões dificilmente são trabalhadas nas escolas.

A normatividade dos currículos e da estrutura das escolas possibilita essa perspectiva segmentada de processos complexos, induzindo uma educação ambiental que pretende ensinar as regras para um comportamento ecologicamente correto, sem que haja reflexão sobre as questões apontadas acima. A "Pedagogia dos 3Rs" (Reduzir, Reutilizar e Reciclar), de acordo com Layrargues (2011), tende a valorizar apenas um dos três "Rs" - reciclar, e tem sido privilegiada nas escolas. O autor também entende que essa abordagem está inscrita na lógica da racionalidade econômica, quando nos valemos de tecnologias como a reciclagem para compensar os prejuízos de uma cultura do consumismo e do desperdício. Além disso, temos a aceleração do consumo gerado pelo tipo de produção, se considerarmos, por exemplo, a obsolescência planejada e a descartabilidade dos produtos. Ainda pouco se observa a abordagem sobre o consumismo, que gera uma quantidade insustentável de resíduos, ou seja, teríamos um quarto "R", o recusar, que dificilmente chega a fazer parte da agenda ecológica do debate nas escolas. Há um grande investimento na prescrição de atitudes e mudança de comportamento - separar os resíduos - e pouco investimento em refletir sobre o consumo na sociedade capitalista, visando o recusar e o reduzir.

Ao buscarmos outros locais de pesquisa, além da violência e do lixo - efeitos produzidos pelos seres humanos que tendem a dificultar sua aproximação da natureza - outro desafio se colocava entre as escolas e as áreas preservadas. Em visita à Escola Superior de Agricultura Luiz de Queiroz (ESALQ), campus da Universidade de São Paulo (USP) localizado em Piracicaba, SP, nosso objetivo foi conhecer as áreas preservadas ${ }^{7}$ e as atividades que eram realizadas nesses locais, procurando identificar ações de ambientalização que envolviam estudantes e funcionários da universidade e a comunidade externa, incluindo as escolas. Na ocasião, havia uma epidemia de Febre Maculosa Brasileira (FMB) na região, a qual é causada por uma bactéria transmitida pelo carrapato-estrela. A FMB provoca uma enfermidade infecciosa febril, de gravidade variável, mas houve na época casos de óbito de pessoas infectadas no município, incluindo o filho de um funcionário da ESALQ.

Algumas capivaras, hospedeiras do carrapato-estrela, possuem a bactéria causadora da FMB e podem transmiti-la aos humanos. Como elas estão presentes em grande número no campus, em especial nas áreas preservadas, todas as atividades que ali ocorriam estavam suspensas, o que incluía as ações de educação ambiental direcionadas às escolas da região. Devemos ter em conta, também, as opões de manejo das populações de capivara, que exigem estudo e enquadramento legal. Assim, observamos que a dinâmica dos ecossistemas, com relação às populações e às cadeias alimentares das capivaras, dos

\footnotetext{
7 Essas áreas são denominadas "Reservas Ecológicas USP” e foram instituídas pela universidade em 2012, sendo administradas pela Superintendência de Gestão Ambiental (SGA/ USP). Informações disponíveis em: <http://www.sga.usp.br/?page_id=164>. Acesso em 06 nov. 2015.
} 
carrapatos-estrela, das bactérias causadoras da FMB e dos humanos, vinha desafiado as vivências junto à natureza no campus da ESALQ (Muhle; Frizzo, 2016). Desta vez, um fator ecológico e não-humano se impunha na relação, e a própria natureza provocava o afastamento dos seres humanos.

Como vimos, a proximidade geográfica das áreas naturais não é garantia de uma aproximação pedagógica com a natureza e de ambientalização curricular. Esta situação também aparece em outras pesquisas como a realizada por Rocha et al. (2017). O objetivo foi compreender as relações entre escolas e a Área de Relevante Interesse Ecológico de Santa Helena, unidade de conservação do município de Santa Helena, Paraná. Os autores observaram que as ações das escolas eram esporádicas e que a educação ambiental não saia do espaço escolar a fim de articular-se à unidade de conservação, o que pode ser comparado às escolas visitadas no nosso estudo.

Nas experiências que identifiquei nas minhas primeiras incursões no campo pude perceber como agentes humanos e não humanos (carrapato-estrela) acabam por gerar barreiras para uma proximidade com os ambientes naturais, impedindo o desenvolvimento de atividades de educação ambiental. Dessa forma, dificultam a aproximação com as áreas preservadas, se constituindo como obstáculos para a ambientalização das escolas visitadas. Por outro lado, situações como esta são boas para pensar a natureza para além das idealizações de uma natureza boa e bela. Aqui se pode ver que no âmbito do que chamamos "natureza" também existem relações de conflito. A ideia de que a dinâmica da natureza inclui certos desequilíbrios é importante para restituir um conceito mais realista de nossas relações com os ambientes naturais. Neste caso, a disseminação do carrapato-estrela se deve à expansão de uma população de capivaras que aumentou pela falta de predadores no território do campus. E, de nosso ponto de vista, esta é ainda uma lição importante de educação ambiental.

\section{MAIS QUE UMA TARDE EM ITAPUÃ: as estratégias da escola Frei Pacífico}

Finalmente, após ter identificado várias dificuldades das escolas em relação às unidades de conservação das quais estavam próximas, localizei uma experiência onde a relação entre uma escola e uma unidade de conservação, no caso um Parque Estadual, não estava impedida pelas razões anteriores e pude, assim, observar outros aspectos da ambientalização curricular. Trata-se da Escola Municipal de Ensino Fundamental (EMEF) Frei Pacífico, próxima ao Parque Estadual de Itapuã (PEI), onde se deu grande parte do meu estudo. A escola e o parque pertencem ao segundo distrito de Viamão, ao sul do município, distando 57 quilômetros de Porto Alegre e 36 quilômetros da sede municipal de Viamão.

A escola foi fundada em $1^{\circ}$ de março de 1964, criada a fim de atender a comunidade da Colônia de Itapuã, a partir da ampliação de uma pequena escola particular que havia no Hospital Colônia de Itapuã $(\mathrm{HCl})^{8}$. Até os anos 2000, a escola funcionava em um pequeno prédio atrás da igreja do $\mathrm{HCl}$, mas a demanda aumentara e não havia estrutura para acomodar um maior número de estudantes, surgindo a necessidade de mudança de local. Gestão e comunidade acordaram que a construção da nova escola deveria observar o fato de estar localizada próxima ao PEI. Em parceria com o Núcleo Orientado para a Inovação da Edificação (NORIE) da UFRGS, decidiu-se que deveriam buscar um projeto de construção sustentável e ter em conta a presença indígena em Itapuã. A nova sede foi inaugurada em 2007, com a missão de ser um modelo de aprendizado sustentável no município de Viamão.

Além da arquitetura, a história da escola Frei Pacífico mostrou que a preocupação com as questões ambientais não era algo recente. Desde a sua criação, dentro da área do $\mathrm{HCl}$, já se trabalhavam aspectos sobre a conservação da natureza e sobre a importância do PEl. Mais recentemente, nos anos 2010, foram ofertadas oficinas de educação ambiental para os estudantes, a escola participou da Conferência

\footnotetext{
${ }^{8}$ O Hospital Colônia Itapuã foi inaugurado em 1940, sendo o último "leprosário" dos 37 construídos em todo o país, como resultado de políticas internacionais para o controle da hanseníase. O hospital trouxe novos moradores para a região, principalmente os funcionários da instituição.
} 
Municipal Infantojuvenil pelo Meio Ambiente e a Comissão de Meio Ambiente e Qualidade de Vida na Escola (COM-VIDA) ${ }^{9}$ foi criada.

A partir do convite para a participação no grupo das escolas inovadoras da Secretaria Municipal de Educação (SME) de Viamão ${ }^{10}$, em 2016 fora instituído o projeto "Aprendizagem Sustentável: uma prática para um mundo melhor", cujo foco na escola era a sustentabilidade. O projeto incluía atividades que já ocorriam na escola, como as oficinas, entre as quais a COM-VIDA, além da modificação na oferta de disciplinas e na carga horária dos professores. Entre segunda-feira e quinta-feira ocorriam as aulas dos componentes curriculares Língua Portuguesa, Artes, Educação Física, Língua Estrangeira - Inglês, História, Geografia, Ciências e Matemática e nas sextas-feiras eram trabalhados Projetos. Semanalmente eram realizadas reuniões de planejamento da disciplina de Projetos e outras demandas, com a presença de todos os professores e da equipe diretiva.

Nas sextas-feiras, as turmas dos Anos Finais eram misturadas e compunham quatro grupos, cada qual atendidos por dois professores de diferentes áreas de conhecimento. Em cada turma, os estudantes se dividiam em grupos menores e trabalhavam em um projeto cujo tema era escolhido por eles, relacionado ao "eixo" ou "tema gerador" selecionado para aquele trimestre. Conforme dito por uma das professoras, a escola estava em uma "imersão ambiental", em relação estreita com o Parque Estadual de Itapuã, com o Hospital Colônia Itapuã e com a comunidade. Assim, os eixos do projeto tinham como função coordenar e ampliar o conceito de sustentabilidade. Ela também explicou que a educação sustentável era a proposta da escola, não apenas uma estratégia de trabalho.

Em 2016, os temas escolhidos foram "Ecológico", no primeiro trimestre, seguido por "Social e Econômico" e "Histórico, Cultural, Turístico", nos trimestres subsequentes. Entre os assuntos de pesquisa escolhidos pelos grupos de estudantes no primeiro trimestre estavam "Mata Ciliar", "Alimentação Saudável”, “Água”, “Parque Estadual de Itapuã”, “Dengue”, “Biodiversidade”, “Plantas Exóticas e Nativas" e "Arquitetura da Escola".

A metodologia de projetos tem sido utilizada em outras escolas brasileiras, mas destacamos, com relação à Frei Pacífico, a presença de estudantes de diferentes etapas de escolarização no mesmo grupo, a docência compartilhada, a possibilidade de eleição de temas de pesquisa pelos discentes e o planejamento realizado em conjunto pelos professores. O levantamento nacional realizado por Trajber e Mendonça (2007) com base no Censo Escolar já mostrava que a educação ambiental era abordada nas escolas predominantemente na forma de projetos e de ações integradas no período investigado, entre 2001 e 2004.

Atualmente, diferentes trabalhos abordam experiências de projetos realizados em escolas próximas a unidades de conservação. Souza e Aguiar (2018), por exemplo, promoveram atividades em duas escolas localizadas no entorno da Reserva Biológica do Jaru, Rondônia, e avaliaram a percepção ambiental dos estudantes, antes e depois das ações. Como resultado, observaram mudanças na percepção dos alunos em relação às temáticas trabalhadas, principalmente no seu agir cotidiano, como a atenção com a reciclagem e com o reaproveitamento de materiais.

A pesquisa de Rocha et al. (2017), mencionada no tópico anterior, mostrou que a falta de proximidade entre escolas e unidades de conservação está relacionada à escassa inserção das políticas públicas de educação ambiental nas instituições. Assim, entendemos que o acesso às políticas e a continuidade das propostas são fatores elementares para o currículo. Uma garantia para a perenidade das ações seria a inclusão das questões ambientais no Projeto Político-Pedagógico das escolas. No caso

\footnotetext{
${ }^{9}$ Com o objetivo de inserir a educação ambiental de forma permanente nas práticas pedagógicas na Educação Básica, o Programa Dinheiro Direto na Escola - Escolas Sustentáveis fomenta a criação da COM-VIDA como elemento estruturante na constituição de espaços educadores sustentáveis (Brasil, 2014).

${ }^{10}$ A SME/Viamão também tinha como proposta o "Projeto do Meio Ambiente", que era estendida para todas as escolas da rede. Em 2016, o tema do projeto estava relacionado à a epidemia da dengue. Na escola Frei Pacífico as atividades eram desenvolvida pela COM-VIDA.
} 
da Frei Pacífico esse processo estava em andamento, e a escola aproveitava as oportunidades de políticas federais, como o Programa Mais Educação, e do município de Viamão, com o projeto das escolas inovadoras.

Em contraponto, a falta de continuidade nas atividades relacionadas às questões ambientais e o envolvimento de uma pequena parcela de professores foi observada em outras escolas que visitei em 2015, e também é apontada por diversos autores. A pesquisa de Machado (2014), por exemplo, mostrou que as iniciativas de trabalhar com a educação ambiental nas escolas partiam de um ou de poucos professores e estavam inseridas em atividades pontuais, relacionadas a datas comemorativas ou a alguns conteúdos das disciplinas de Ciências e de Geografia.

O protagonismo de apenas alguns professores no processo de ambientalização da escola também foi observado nas pesquisas de Borges (2014) em duas redes locais de educação ambiental do sul do Brasil, e de Grohe (2015), em escolas de São Leopoldo, RS. Os autores destacam a orientação ecológica desses atores, o que também foi observado na Frei Pacífico. Além das ações relacionadas às práticas pedagógicas e a opção por um espaço físico sustentável, a Frei Pacífico contava com uma equipe diretiva e um grupo de professores simpáticos à temática ecológica. Mesmo com as alterações no quadro docente, os professores novos que chegavam à escola tendiam a ser absorvidos por tal motivação.

A escola buscava uma relação de proximidade com o Parque Estadual de Itapuã, participando das atividades promovidas pela unidade de conservação e convidando a instituição para o planejamento e para a execução de ações conjuntas, tais como palestras e caminhadas orientadas nas trilhas. A intenção da escola era dar importância à região, o que incluía no currículo a valorização do $\mathrm{PEI}$ e do $\mathrm{HCl}$, por exemplo.

Assim como consideramos a ambientalização de forma ampla, como mencionado anteriormente, acreditamos que o currículo também circunscreve uma gama mais complexa de ações, não podendo ser reduzido a listas de componentes curriculares e de conteúdos a serem abordados ao longo do ano letivo. Compreendemos o currículo como experiência educativa, com seu desenvolvimento na prática, sendo construído ao longo do processo. Nesse sentido, concordamos com Sacristán (2000), que considera o currículo como um processo que envolve uma multiplicidade de relações, desde as decisões administrativas e as práticas pedagógicas, as propostas e a ação, até a escola como instituição e como uma unidade social. Para o autor, o currículo acontece no contexto da prática, ao mesmo tempo em que é contextualizado por ela. Além dele, Barriga (2012) também corrobora nesta direção, compreendendo o currículo como ação, acreditando que os avanços se dão a partir da constituição de uma racionalidade que emane da prática.

As ações aqui elencadas, relacionadas à gestão, ao espaço físico e às práticas pedagógicas, bem como o reconhecimento da importância do lugar e a história da escola, corroboravam com o processo de ambientalização da Frei Pacífico. Com o foco na sustentabilidade e na valorização de Itapuã, o currículo, na prática, era desafiado e reinventado pelo grupo de professores e gestores da Frei Pacífico.

\section{A NATUREZA VENCEU EM ITAPUÃ. E quem perdeu?}

As políticas para a conservação da natureza no Brasil sofreram, em um primeiro momento, a influência da perspectiva que surgira inicialmente nos Estados Unidos no século XIX, com o objetivo de proteger a vida selvagem do avanço da civilização urbano-industrial (Diegues, 2000). Essa visão tradicional está relacionada principalmente à gênese da construção de políticas no país, mas ainda permaneceu no SNUC de 2000, com a manutenção de unidades de conservação de proteção integral. Em contraponto, a lei comporta categorias de uso sustentável, como as reservas extrativistas, que permitem a permanência no interior do seu território antigos moradores, considerados como populações tradicionais. Sua criação resultou da mobilização dos grupos sociais extrativistas e da sociedade, à exemplo dos seringueiros da Amazônia nos anos 1970 e 1980. 
Na sequência, em diferentes lugares do país houve apoio para a implementação de unidades de conservação, sendo os grandes centros urbanos - Sul e Sudeste - os principais locais onde entidades ambientalistas foram criadas para promover tais ações, inclusive destinadas a outras regiões do país, como a Amazônia.

No caso de Itapuã não foi diferente, já que em 1985 foi criada a Comissão de Luta pela Efetivação do Parque Estadual de Itapuã (CLEPEI), composta por representantes da Associação Gaúcha de Proteção ao Ambiente Natural, da Fundação Pró-Natureza, da Fundação Brasileira para Conservação da Natureza e dos diretórios acadêmicos do Instituto de Biociências e da Geologia da UFRGS. A maior preocupação, na época, era a atividade das pedreiras nos morros em Itapuã. Para a extração do granito eram necessárias explosões, deslocamento de veículos pesados e áreas para acampamento e moradia dos "cortadores de pedra" - como chamavam aqueles que trabalhavam nas pedreiras -, o que provocava grandes alterações nos ecossistemas.

Poucos moradores se envolveram com os movimentos em prol da efetivação do PEl, o que foi reforçado na fala de uma funcionária do parque: "O Parque Estadual de Itapuã foi conquistado pelos ambientalistas". Assim, tratava-se de uma demanda exógena, não local, constituída principalmente por atores de fora da comunidade de Itapuã. Tal fato já foi observado em muitos lugares, ou seja, os movimentos ambientalistas dificilmente nascem nas comunidades locais; ao contrário, se observa uma tendência exógena na configuração de movimentos de apoio à implantação de unidades de conservação.

Assim, observamos, em nosso campo de pesquisa, um conflito socioambiental relacionado à implantação das unidades de conservação. As políticas de conservação, no caso, à luz do SNUC, conduziram a saída das pessoas que viviam ou trabalhavam no local a fim de conservar aquela parcela natural destinada ao Parque Estadual de Itapuã. Como já mencionado, as políticas brasileiras tiveram como base o modelo estadounidense, o qual reforçou ainda mais a dicotomia humano/natureza, no caso, separando os povos dos parques (Diegues, 2000). Os movimentos em defesa das unidades de conservação, bem como os critérios de avaliação das áreas a serem preservadas, estão muito ligados às ciências naturais e ao seu destino como áreas de pesquisa científica, contando com pouca ou nenhuma participação das comunidades locais.

Como efeito das ações dos ambientalistas, as pedreiras encerraram a exploração na década de 1980. Porém, no mesmo período iniciou-se a especulação imobiliária de veranistas, que construíram casas nas praias para utilizar nas férias e nos finais de semana. Ocorreu o desmatamento para a criação um loteamento ilegal na praia de Fora, o qual continha cerca de 800 casas. Com as construções vieram outros problemas, como a substituição da vegetação nativa por espécies exóticas, plantadas para viabilizar locais de sombra nas praias, e as queimadas acidentais, causadas pelas fogueiras ou pelo descarte de cigarros acesos, por exemplo. Esses fatores levaram ao fechamento do parque para a visitação pública e a criação da unidade de conservação em março de 1991.

Após a retirada das casas construídas no loteamento, o PEI permaneceu fechado por cerca de dez anos, entre 1992 e 2002, a fim de construir uma infraestrutura para receber visitantes e pesquisadores. Com o passar de uma década, a natureza se recuperou, sendo visível o avanço da vegetação e o aparecimento ou o aumento da população de alguns animais. Este é, sem dúvida, efeito da conservação; é efeito do isolamento da natureza à presença humana, como se os seres humanos não fossem parte dela. Não fazendo parte, neste caso, no sentido de viver no local; no entanto, fazendo parte como decisores de seu isolamento.

Os ecossistemas se beneficiaram e houve uma recuperação das áreas desmatadas, o que justifica a frase destacada pelos ambientalistas em um cartaz no Centro de Visitantes do PEl: "A natureza venceu em Itapuã". Tal afirmação, no entanto, leva à questão: quem perdeu?

Como já mencionado, Parque é uma categoria de Unidade de Conservação de Proteção Integral, ou seja, prevê a "manutenção dos ecossistemas livres de alterações causadas por interferência humana" na área delimitada (Brasil, 2000). Assim, para a implantação do PEI, muitas pessoas foram retiradas - por 
ação de despejo no caso daqueles que construíram casas nas praias em 1991, ou pelas desapropriações em curso desde $1973^{11}$. Muitos dos moradores não foram indenizados como gostariam, seja por não terem direito (no caso do loteamento clandestino), ou pelos valores oferecidos e a morosidade nos processos judiciais, alguns em curso até hoje. De fato, ainda que dentro dos procedimentos legais, as expropriações geraram um sentimento muito grande de injustiça. Fabrício, guarda-parque do PEI, questionou o conhecimento das pessoas com relação à existência das unidades de conservação, já que se tratavam de locais isolados, "sem humanos". As pessoas não podiam visitar livremente, conhecer ou morar nessas áreas, o que o levou a afirmar: "É como se [as unidades de conservação] não existissem".

As ações aplicadas com base na legislação das unidades de conservação, aliadas aos conflitos com as pessoas que tinham sido atingidas pelo PEl, de fato afastaram ainda mais a comunidade. De acordo com o morador Enzo, "Os biólogos travaram tudo por causa da pedreira". A afirmação de Lucas, que também reside em Itapuã, corrobora com nossa reflexão: "Eu sempre gosto de ver aquele lado do impacto que uma unidade de conservação provoca numa comunidade". Em suas falas podemos compreender que o saber científico - que justificava a necessidade de preservação do ambiente - e o poder do Estado, que instituiu a unidade de conservação, eram compreendidos de outra forma pela comunidade. Quem utilizava a área anteriormente, para lazer, moradia ou trabalho, por exemplo, não aceitou a proibição de entrada ou a expulsão daqueles que lá viviam. Cabe também mencionar que o parque esteve fechado para a visitação em outros momentos, principalmente por problemas de manutenção da estrutura e a carência de recursos humanos, o que também contribui com a insatisfação e o afastamento entre a unidade de conservação e a comunidade de Itapuã. Os período de fechamento, bem como a cobrança de taxa para o ingresso, o limite de pessoas por dia (capacidade de suporte) e as regras para o uso da área são questões que, atualmente, provocam descontentamento nos visitantes.

Mesmo com todos esses conflitos, a grande maioria dos interlocutores afirmou que se o PEI não tivesse sido implantado hoje não haveria mais ambientes naturais preservados. Vários citaram a presença de capivaras e de outros animais que antes não eram vistos na área. Dessa forma, mesmo aqueles que se mostravam mais contrariados com a unidade de conservação acabavam por fazer a defesa da preservação da natureza. Assim, observamos aqui outro conflito, que se expressa na oposição entre a proteção da natureza e o uso limitado da área. Ana, por exemplo, afirmou: "Eu acredito nesses argumentos [restrição do uso para preservação] que dizem pra gente" "12, compreendendo que, se não houvesse a implantação da unidade de conservação, a natureza seria "destruída".

Assim, de um lado "a natureza venceu", mas os conflitos aqui registrados mostram que muitas pessoas "perderam" com a implantação do Parque Estadual de Itapuã, tendo que adaptar seu modo de vida, buscar novos locais para morar, para trabalhar e para o lazer. Apesar de todos os anos que se passaram desde a efetivação do PEl, ainda há divergências com a comunidade. De acordo com o que foi observado no estudo, os conflitos estavam relacionados a problemas do passado que ainda não tinham sido resolvidos, tais como as indenizações sobre as terras desapropriadas, a promoção de alternativas de trabalho e as regras restritivas para o acesso à área, bem como aos limites de uso impostos pela unidade de conservação. Esses fatores são o reflexo das políticas de conservação da natureza que constituíram as unidades de conservação no Brasil, especialmente nos anos 1980 e 1990, sem considerar as necessidades das comunidades que viviam dentro e no entorno das áreas (Frizzo, 2018). Ou seja, a ideia de preservação da natureza como antagônica ao diálogo com as populações, uma vez que preservação, nesta acepção, considera todo uso humano nocivo para a preservação.

\footnotetext{
${ }^{11}$ A área do PEI, de 5.566,50 hectares, é oriunda de terras desapropriadas pelo Estado do Rio Grande do Sul entre as décadas de 1970 e 1990.

${ }^{12}$ Ana se refere às pessoas que, na época e em vários momentos até hoje, procuram justificar a implantação do PEI para a preservação da natureza, a fim de valorizar a unidade de conservação e de buscar uma aproximação com a comunidade.
} 


\section{CONSIDERAÇÕES FINAIS}

Ao longo deste artigo procuramos apresentar algumas situações que mostram os diferentes caminhos que podem tomar as relações entre escolas próximas de unidades de conservação e estes espaços naturais. Discutimos as estratégias utilizadas para a ambientalização do currículo onde o acesso às áreas naturais não está impedido por fatores sociais e ecológicos, conforme resultados da pesquisa realizada em Viamão e Porto Alegre, RS, entre 2014 e 2018.

A partir da escola Frei Pacífico, observamos diferentes fatores que influenciavam o cotidiano escolar e a constituição do currículo e da escola na prática, especialmente no que se refere à ambientalização. Certos elementos facilitam a aproximação entre essas instituições e as unidades de conservação, como os investimentos dos gestores e funcionários das unidades de conservação na promoção da educação ambiental nas escolas, a presença de professores e de gestores engajados com as questões ambientais, e os incentivos das políticas públicas, como o Programa Mais Educação e a legislação referente à educação ambiental.

Por outro lado, alguns desafios se impõem à aproximação entre as escolas e as unidades de conservação, entre eles o número reduzido de funcionários nas unidades de conservação e a pouca disponibilidade de recursos financeiros. Também mostramos que agentes não humanos (carrapatoestrela) e os próprios seres humanos (violência) constituem obstáculos para a relação com a natureza. Perspectivas muito fechadas que norteiam algumas ações ambientais, bem como políticas que estabelecem certa rigidez ao currículo ao determinar tempos e normas pouco flexíveis e matrizes curriculares mínimas engessadas também podem dificultar os processos de ambientalização e de aproximação com as unidades de conservação. Ao mesmo tempo, a imposição das regras de acesso e de uso das unidades de conservação colocam a comunidade em uma posição de contrariedade, o que se soma aos conflitos históricos da implantação das unidades de conservação no Brasil, os quais estão relacionados à perspectiva de isolamento das áreas a serem protegidas.

Nem sempre o fato da escola estar localizada próxima ou dentro de uma unidade de conservação estimula sua aproximação com a mesma, a preocupação com as questões ambientais ou a ambientalização do currículo. De forma complexa, elementos como o investimento de gestores para a parceria entre escolas e unidades de conservação, o engajamento dos professores e o incentivo das políticas públicas, além de outros fatores que podem não ter sido observados na pesquisa realizada, cooperam para que esses processos se constituam na prática nas escolas.

Por fim, reafirmamos nossa crença na valorização de todas as formas de vida e de saberes, e na aposta para uma formação humana integral e ambientalmente orientada. Assim, apostamos no estreitamento da relação entre escolas e unidades de conservação, o que traria ganhos para ambos os lados. Isto significa ampliar a educação ambiental para além das áreas protegidas e internalizar as questões relativas ao ambiente e à natureza no coração da vida escolar, tornando-as parte do currículo.

\section{REFERÊNCIAS}

BARRIGA, Ángel Díaz. Curriculum: una mirada sobre su desarrollo y sus retos. In: WESTBURY, Ian. ¿Hacia donde va el curriculum? La contribuición de la teoria deliberadora. Massanet de la Selva (Girona): Ediciones Pomares, 2012. p. 163-175.

BORGES, Marcelo Gules. Formas de aprender em um mundo mais que humano: emaranhados de pessoas, coisas e instituições na ambientalização do contexto escolar. 2014. 197f. Tese (Doutorado em Educação) - Programa de Pós-Graduação em Educação, Pontifícia Universidade Católica do Rio Grande do Sul, Porto Alegre, 2014.

BRASIL. Lei no 9.985, de 18 de julho de 2000. Regulamenta o art. 225, §1, incisos I, II, III e VII da Constituição Federal, institui o Sistema Nacional de Unidades de Conservação da Natureza e dá outras 
providências. Brasília, 18 jul. 2000. Disponível em: <http://www.planalto.gov.br/ccivil_03/leis/l9985.htm>. Acesso em: 06 mai. 2014.

BRASIL. Ministério da Educação. Secretaria de Educação Continuada, Alfabetização, Diversidade e Inclusão. Diretoria de Políticas de Educação em Direitos Humanos e Cidadania. Coordenação-geral de Educação Ambiental. Programa Dinheiro Direto na Escola - PDDE Escolas Sustentáveis - Guia de Orientações Operacionais. Brasília, 2014. Disponível em:

<http://pdeinterativo.mec.gov.br/arquivo/pdf/Guia_PDDE_2014_Sustentavel.pdf >. Acesso em: 01 abr. 2015.

CARVALHO, Isabel Cristina Moura. Paisagem, historicidade e ambiente: as várias naturezas da natureza. Paisagem, historicidade e ambiente: as várias naturezas da natureza. Confluenze, Bolonha, v. 1, n. 1, p. 136-157, 2009.

CARVALHO, Isabel Cristina de Moura; FARIAS, Carmen Roselaine; PEREIRA, Marcos Villela. A missão "ecocivilizatória" e as novas moralidades ecológicas: a educação ambiental entre a norma e a antinormatividade. Ambiente e Sociedade, Campinas, v. 14, n. 2, p. 35-49, jul./dez. 2011.

CARVALHO, Isabel Cristina Moura; TONIOL, Rodrigo. Ambientalização, cultura e educação: diálogos, traduções e inteligibilidades possíveis desde um estudo antropológico da educação ambiental. Revista Eletrônica do Mestrado em Educação Ambiental, Rio Grande, v. 1, p. 28-39, 2010.

DEBETIR, Emiliana. Gestão de unidades de conservação sob influência de áreas urbanas: diagnóstico e estratégias de gestão na Ilha de Santa Catarina - Brasil. 2006. 247 p. Tese (Doutorado em Engenharia Civil) - Programa de Pós-Graduação em Engenharia Civil, Universidade Federal de Santa Catarina, Florianópolis, 2006.

DIEGUES, Antonio Carlos Santana. O mito moderno da natureza intocada. 3. ed. São Paulo: Hucitec Núcleo de Apoio à Pesquisa sobre Populações Humanas e Áreas Úmidas Brasileiras, USP, 2000.

FARIAS, Carmem Roselaine de Oliveira. A ambientalização do currículo do ensino básico segundo nossos olhares e práticas de pesquisa. In: CONGRESO INTERNACIONAL SOBRE INVESTIGACIÓN EN DIDÁCTICA DE LAS CIENCIAS, 9., 2013, Girona: 2013. Anais do IX Congresso Internacional sobre Investigación en Didáctica de Las Ciencias. Girona, 2013. Disponível em <http://www.raco.cat/index.php/Ensenanza/article/view/307065>. Acesso em 11 dez. 2017.

FORQUILHA, Salvador. Inquérito de Terreno: É possível falar de rigor em metodologias qualitativas? Em que condições e usando que critérios? Maputo: IESE, 2013. Disponível em <http://www.iese.ac.mz/lib/publication/outras/TD/TD-SF.pdf>. Acesso em 13 nov. 2015.

FRIZZO, Taís Cristine Ernst. Educação e Natureza: os desafios da ambientalização em escolas próximas a unidades de conservação. 2018. 281 f. Tese (Doutorado em Educação) - Programa de Pós-Graduação em Educação, Pontifícia Universidade Católica do Rio Grande do Sul, Porto Alegre, 2018. Disponível em: <http://tede2.pucrs.br/tede2/handle/tede/8085>. Acesso em: 30 mai. 2018.

LAYRARGUES, Philippe Pomier. O cinismo da reciclagem: o significado ideológico da reciclagem da lata de alumínio e suas implicações para a educação ambiental. In: LOUREIRO, Carlos Frederico Bernardo; LAYRARGUES, Philippe Pomier; CASTRO, Ronaldo Souza de. Educação ambiental: repensando o espaço da cidadania. São Paulo, Cortez, 2011. p. 185-225.

LEITE LOPES, José Sergio. Sobre processos de ambientalização dos conflitos e sobre dilemas da participação. Horizontes Antropológicos, Porto Alegre, v. 12, n. 12, p. 31-64, 2006.

LOUREIRO, Carlos Frederico Bernardo; AMORIM, Érica Pereira; AZEVEDO, Luísa; COSSÍO, Maurício 
Blanco. Conteúdos, Gestão e Percepção da Educação Ambiental nas Escolas. In: TRAJBER, Rachel; MENDONÇA, Patrícia Ramos. (orgs.) Educação na diversidade: o que fazem as escolas que dizem que fazem educação ambiental. Brasília: Secretaria de Educação Continuada, Alfabetização e Diversidade, 2007. p. 35-79.

GROHE, Sandra Lilian Silveira. Escolas Sustentáveis: três experiências no município de São Leopoldo - RS. 2015. 135 f. Dissertação (Mestrado em Educação) - Programa de Pós-Graduação em Educação, Pontifícia Universidade Católica do Rio Grande do Sul, Porto Alegre, 2015.

MACHADO, Júlia Teixeira. Educação ambiental: um estudo sobre a ambientalização do cotidiano escolar. 2014. 246 f. Tese (Doutorado em Ciências) - Programa de Pós-Graduação em Ecologia Aplicada, Universidade Estadual de São Paulo, Piracicaba, 2014.

MATOS, Mauricio dos Santos; MARIA, Tathiana Popak. Concepções de ambiente em atividades de educação ambiental desenvolvidas em um parque municipal. Revista Brasileira de Educação Ambiental, São Paulo, v. 8, n. 1, p. 19-29, 2013.

MUHLE, Rita Paradeda; FRIZZO, Taís Cristine Ernst. Quando a natureza afasta o humano. In: LOPES, José Rogério; SILVA, Adimilson Renato da; SCHIERHOLT, Anelise Fabiana Paiva; MEIRELLES, Mauro (orgs.). Panorama das políticas culturais e ambientais no Brasil. V. 2. Porto Alegre: CirKula, 2016. p. 175-188. Disponível em: <https:// drive.google.com/file/d/oB7Hsu_eHH2NUOVNrMlpwNjlOZjg/view>. Acesso em: 01 mar. 2017. ISBN 9788567442693.

NUNES, Letícia B. e CARVALHO, Isabel C. M. Ambientalização do Ensino Médio: impactos do Novo ENEM - 2009. In: MOSTRA DE PESQUISA DA PÓS-GRADUAÇÃO, 5., 2010, Porto Alegre. Anais da V Mostra de Pesquisa da Pós-Graduação. Porto Alegre: EDIPUCRS, 2010. Disponível em: $<$ http://www.pucrs.br/edipucrs/Vmostra/V_MOSTRA_PDF/Educacao/82528LETICIA_BASTOS_NUNES.pdf $>$. Acesso em: 23 set. 2013.

RIO GRANDE DO SUL. Decreto Estadual n. 53.037, de 20 de maio de 2016. Institui e regulamenta o Sistema Estadual de Unidades de Conservação - SEUC. Porto Alegre, 20 de maio de 2016. Disponível em: <http://www.al.rs.gov.br/filerepository/repLegis/arquivos/ DEC\%2053.037.pdf>. Acesso em: 23 out. 2015.

ROCHA, Keili Luci; AHLERT, Alvori; CARNIATTO, Irene. Área de Relevante Interesse Ecológico (ARIE) como espeço para a educação ambiental. Revista Brasileira de Educação Ambiental, São Paulo, v.12, n. 5, p. 10-24, 2017.

SACRISTÁN, José Gimeno. Currículo: uma reflexão sobre a prática. 3 ed. Porto Alegre: Artmed, 2000. SOUZA, Nadir Leandro de. Unidades de Conservação em Áreas Urbanas - o caso Do Parque Cinturão Verde de Cianorte - Módulo Mandhuy. Raega, Curitiba, v. 23, p. 448-488, 2011.

SOUZA, Wesley de; AGUIAR, Renata Gonçalves. Revista Brasileira de Educação Ambiental, São Paulo, v. 13, n. 1, p. 172-191, 2018.

TRAJBER, Rachel; MENDONÇA, Patrícia Ramos. (orgs.) Educação na diversidade: o que fazem as escolas que dizem que fazem educação ambiental. Brasília: Secretaria de Educação Continuada, Alfabetização e Diversidade, 2007.

Recebido em: 23/10/2018

Alterações recebidas em: 09/11/2018

Aceito em: 10/11/2018 